\title{
KNOWLEDGE CREATION AS AN APPROACH TO FACILITATING EVIDENCE INFORMED PRACTICE: EXAMINING WAYS TO MEASURE THE SUCCESS OF USING THIS METHOD WITH EARLY YEARS PRACTITIONERS IN CAMDEN (LONDON)
}

\section{Dr. Chris Brown and Dr. Sue Rogers, Institute of Education, University of London}

Key words: evidence informed practice; measures of evidence informed practice; expertise in evidence use; measuring evidence use; knowledge creation; early years; early years foundation stage; EYFS.

\section{Introduction}

This paper has three key aims. First it examines the authors' attempts to use knowledge creation activity as a way of developing evidence informed practice amongst a learning community of 36 early years practitioners in the London Borough of Camden. Second, situating the idea of effective evidence use within Flyvbjerg's notion of expertise, it seeks to illustrate how the authors approached the idea of measuring evidence use. Specifically, how we sought to ascertain whether early years practitioners, having been continually engaged in knowledge creation activity, were developing expertise as evidence users. As part of this second aim, we examine our engagement with two separate measurement scales: the 'ladder of research use' and Hall and Hord's (2001) Levels of Use scale. Finally we explore how we sought to examine the 'trustworthiness' of our approaches to measuring evidence use, via the use of in-depth semi structured interviews. We conclude by assessing our approach, examining both its strengths and limitations, and also highlighting other contexts and situations in which it might be used.

\section{Evidence-informed practice}

The notion of using evidence to aid practice is not without controversy or debate. For example, much has been written regarding whether the evidence-informed movement serves to work against practitioners' professional judgment (e.g. see Biesta, 2007; Brown, 2014). Likewise, there exists issues in relation to how formal academic knowledge and professional or tacit knowledge might be effectively combined (Stoll, 2009; Brown, 2013). Furthermore are the still very active and virulent disputes surrounding some of the methods commonly associated with enhancing evidence use (e.g. randomized control trials and the process of systematic review - see Maclure, 2005; Nutley et al., 2007; Brown, 2013; Goldacre, 2013). A final aspect of note centers on how practitioners' capacity to engage with academic research might be enhanced (e.g. Hargreaves, 1996; Cooper et al., 2009). This final issue is also 
intertwined with the notion that much academic research is inaccessible to teachers, both in terms of where it is published and the language that is typically used within such publications (Hillage et al., 1998; Tooley and Darby, 1998). Not withstanding these issues, this paper is grounded in the idea that engaging with evidence is socially beneficial: that using evidence can develop our understanding of the world via an exposure to ideas and concepts we might not ordinarily come across. In turn, that this exposure potentially enhances the repertoire of 'understanding' upon which we can draw as we develop solutions to the issues of practice.

In itself, being evidence-informed is a somewhat nebulous notion and it is difficult to conceptualise what a state of evidence-informed might 'look like'. It is unlikely, for example, that evidence will ever inform practice in a 'pure' form: i.e. that acts of practice will be instigated and will follow exactly what was intended by the researcher. Instead evidence must conjoin with contextual and other practice related factors and any decision made will be a function of all of these (Virtanen and Tynjälä, 2008; Rexvid et al., 2012; März and Kelchtermans, 2013). This is reflected by England's Department for Education (DfE), who define evidence-informed practice in the following way:

Evidence based practice is a combination of practitioner expertise and knowledge of the best external research, and evaluation based evidence.

(www.education.gov.uk, 2014: authors' emphasis)i.

The DfE's notion of what it is to be evidence-informed, however, highlights three key issues in relation to the concept. The first is the need to conceive of how such combinations of formal and practitioner held knowledge might be meaningfully realized (i.e. from a theoretical perspective, what represents successful combination of knowledge types). The second issue is the requirement for researchers to conceive of approaches that will enable us to combine formal and practitioner held knowledge in accordance with this theory, so that a state of 'evidence-informed' is achieved. Last, there is the onus to devise ways of measuring whether we have reached our destination: that is, based on our theoretical perspectives and practical approaches, how might we ascertain whether practitioners are now informed by evidence? We now use the remainder of the paper to discuss these issues in more detail before examining our attempts to tackle them as part of the Camden Early Years Learning Community project.

\section{Expertise}

Beginning with the first of these issues, our suggestion is that an effective way to conceptualize the combination of knowledge types described above, is by considering 
Flyvbjerg's notions of 'expertise' in relation to evidence use. Flyvbjerg (2001) employs the 'Dreyfus' model of learning to illustrate what he means by expertise; an approach that employs five 'levels' of human learning, ranging from novice to expert. ${ }^{\text {ii }}$ What the Dreyfus model clarifies is that each of these five levels comprises recognisably different behaviours in relation to the performance of a given skill. A novice, for example, will be new to particular situations; will, during instruction, learn about facts corresponding to and other characteristics pertaining to the situation and so is taught or develops 'rules for action'. Correspondingly, Flyvbjerg suggests that for the novice:

Facts, characteristics, and rules are defined so clearly and objectively... that they can be recognised without reference to the concrete situations in which they occur. On the contrary, the rules can be generalised to all similar situations, which the novice might conceivably confront. At the novice level, facts, characteristics, and rules are not dependent on context: they are context independent (2001:11).

Flyvbjerg argues that as learners advance from 'novice' and through the levels of 'advanced beginner', 'competent performer' and 'proficient performer', that a number of things occur to facilitate the normalisation of more instinctual/intuitive behaviour. First, instances of performing in real life situations increase, as a result the number of 'cases' that the learner encounters and tackles also increases. Second, recognition of different situations accumulate, as does recognition of the context in which those situations occur. Third, dependency on specific 'rules for action' diminishes as learners are able to interpret and judge how to perform optimally in any given situation. Genuine expertise, however, only occurs as the result of 'quantum leap' in behaviour and perception. Specifically, expertise results as an individual moves from being from being an analytical problem solver to someone who: "[exhibits] thinking and behaviour that is rapid, intuitive, holistic, interpretive... [expertise] has no immediate similarity to the slow, analytical reasoning which characterises rational problem-solving and the first three levels of the learning process" (Flyvbjerg, 2001:14). In other words, true expertise represents a situation in which experience and formal knowledge are intuitively and holistically combined in order that a problem might be immediately assessed and a solution provided almost without conscious reasoning.

Relating this to practitioner evidence-use, it is clear that a spectrum of potential evidence-use types is likely to exist and that this spectrum will range from 'novice' use: i.e. practitioners slavishly following 'what works' type evidence, or mandates or solutions produced on the back of this evidence, to that of expert use. In contrast to novice users, however, expert evidence users are those practitioners who can intuitively develop responses to situations, 
with this intuitive holistic reading based on an amalgamation of the formal research knowledge they have adopted to date, an understanding of the specific case they are dealing with and their understanding of the other environmental factors that might be influence their decision. Since issues in marrying centrally prescribed, 'evidence-based' solutions with local context have been reported in a number of professions (for example, Rexvid et al., 2012; examine doctors' and social workers' reactions to initiatives to implement 'evidence-based' guidance) and there is sometimes a substantial cost in terms of the recontextualisation required with such marrying (e.g. see Cartwright, 2013 who argues that such costs relate to the support factors required to implement solutions in a given setting) we would argue that the most effective types of use stem from evidence being employed in an expert way. As a result that it shouldn't be required that 'best available' evidence is slavishly followed, but that formal knowledge is applied alongside practitioner understanding/data/enquiry in order to frame or define an issue, provide an understanding for how it might be addressed and/or help ensure that data might be analysed most effectively. A fundamental difference then between top-down evidence-informed solutions (e.g. see Moss 2013 for an excellent example) and what occurs in a situation of expert evidence use on the part of practitioners, is that the choice of any formal knowledge engaged with is made by the practitioner such that it best suits their needs, circumstances or priorities. In other words, formal research is filtered through a 'contextual window', which determines what formal research might be considered (for instance, with regards to the nature of the issue and acceptable ways of tackling it).

\section{Professional learning communities}

Having established a theory that accounts for how knowledge might be meaningfully combined, we now consider approaches that enable formal and practitioner held knowledge to be combined in ways consistent with Flyvbjerg's theory of expertise. Here we turn to the notion of professional learning communities. Whilst there is no universal definition of a professional learning community, they are usually depicted as a situation in which people involved with and concerned about schooling work collaboratively to learn about how they can improve pupil learning or outcomes. For example such communities have been described by Stoll (2008: 107) as a means through which to build "learning [in order] to support educational improvement”. Stoll continues by suggesting that professional learning communities comprise: "inclusive, reflective, mutually supportive and collaborative groups of people who find ways, inside and outside their immediate community to investigate and learn more about their practice" (ibid). The notion of professional learning communities thus encapsulates instances where practitioners and researchers might conjoin in order to facilitate learning about and from formalized/academic knowledge. 
Much has been written about what is required for learning communities to function effectively: for example, in terms of the conditions that allow learning communities to flourish or in terms of how knowledge creation and/or 'learning conversation' activity within them is best structured and facilitated (e.g. see Wenger et al, 2002; Stoll et al., 2006; Earl and Timperley, 2008; Stoll, 2012). There is insufficient space within this paper to discuss these aspects in detail, but to note that these conditions and characteristics were considered and executed in the design and operation of our learning community as described below (also see Rogers and Brown, forthcoming). In addition, it should also be noted that in practical terms, learning communities are still very much a nascent form of professional development in education (Seashore-Louis, 2010). Despite this, there is some positive evidence regarding the efficacy of learning communities in enhancing practitioners' use of research knowledge, so that they might better address problems or inform decision-making (ibid). Again this served to reinforce our decision to favour this approach.

Importantly for the purposes of this paper, a key benefit of the professional learning communities approach may be attributed to the nature of the learning that takes place within them, which is encapsulated by the process of knowledge 'creation'; described by Stoll (2008) as one where the producers and users of formal knowledge, who are, respectively, also the users and holders of 'practical' knowledge, come together to create 'new' knowledge (Stoll, however, uses the term 'animation'). Nonaka and Takeuchi (1995) conceptualise this process of creation as one that arises from the interactions that arise between tacit and explicit (or informal and formal) knowledge. In particular a 'spiralling' that accrues from the occurrence of four sequential types of knowledge conversation with the culmination of this process resulting in practioners 'internalising' newly created knowledge and intuitively drawing upon it as part of the day to day process of developing practice-related solutions (in other words it results in a state of expertise). Activities to facilitate knowledge creation activity are considered in detail in Stoll (2009) and we outline our approach in a general sense, further below.

\section{How might we measure evidence use?}

The third issue we highlighted earlier relates to how we might know when any state of 'evidence informed' has been achieved. Researchers' ability to measure the efficacy of approaches to facilitating evidence informed practice have been problematised by Levin, who argues both that:

...even if one recognizes multiple forms of research influence, it is very difficult to identify when these have taken place or how much effect they have had... Most of the 
research assessing research impact relies on one asking people what they did and why, even though it is known that self-reports, whether of belief or behaviour are not reliable...

and:

Practitioners themselves cannot readily disentangle the role of particular influences on complex activities such as professional practice or policy choices (2013: pp. 6-7).

In other words that measures of research use focus on discrete instrumental uses of research (Landry et al, 2003). We argue that the issues raised by Levin are further compounded when incorporating the need to conceive of evidence use as something intrinsically related to expertise. This is because, as will be illustrated below, the levels used to describe expertise seem fiendishly difficult to translate into something that can be surveyed. In other words, based on how we have described the notion of expertise and its relationship to being evidence-informed above, a trickier problem is presented: how might we then measure evidence use in a way that helps us ascertain whether individuals are learning/developing as expert evidence users? We now describe our approach to this issue as undertaken as part of the Camden Early Years Learning Community project.

\section{The Camden Early Years Learning Community project}

Educational provision for children under 5 in the UK is offered within a range of diverse settings including nursery classes, private and voluntary nurseries, children's centres and primary schools. Historically, the fragmented and patchy nature of this provision has created difficulties and divisions for children, their families and practitioners alike. Early childhood services have seen an unprecedented period of investment, development and change since the election of the New Labour government in 1997 and in successive governments. The aim to ameliorate the fragmented nature of early years provision is closely bound up with the desire to reduce child poverty and disadvantage and to encourage more lone parents (and in particular mothers), back to work. Such aspirations have required a major 'root and branch' approach to services for young children and their families (Anning, 2006). Central to this has been the dual aim both to increase the quantity, and improve the quality, of childcare provision. To achieve greater coherence in provision the Early Years Foundation Stage (EYFS) was established in 2008 and revised in 2012. iii The EYFS was devised with the following aims: 
- Setting the standards for children's learning, development and care from birth to statutory school age at 5 ;

- improving quality and consistency in the early years sector;

- laying a secure foundation for future learning through individual learning and development planned around the individual needs and interests of the child;

- providing equality of opportunity; and

- creating the framework for partnership working.

(Tickell, 2012)

Qualifications of staff working with young children are highly variable and match the diversity of provision in the sector. Latest figures suggest that $73 \%$ of staff working in childcare settings is qualified to level 3, the equivalent of an ' $A$ ' level in England. A much lower figure of $7 \%$ is qualified to level 6 or graduate level. In nursery and reception classes within primary schools the figure for graduate level qualification is higher at around $40 \%$ with qualified teacher status (Tickell, 2012). Considerable progress has been made to improve the qualifications of those working with young children. A further challenge, however, is that of continuing professional development in a period of significant change in the policy landscape and in curricular and pedagogical requirements. For example, it is now widely accepted that good pedagogical leadership makes a difference to the quality of early years provision particularly with regard to implementing the EYFS via the provision of an enabling environment and, critically, an enabling pedagogy that meets the complex learning needs of children in the early years (Rogers, 2014).

Against this background, the Camden project responded to a specific identified need to improve the skills and knowledge of a diverse group of practitioners in relation to the requirements of the EYFS. In particular Camden Local Authority and a number of heads of early years settings in the borough argued that support was required with regards to the newly introduced Characteristics of effective learning, which provide the context for learning in the EYFS. These are:

- Playing and exploring - children investigate and experience things, and 'have a go'

- Active learning - children concentrate and keep trying if they encounter difficulties; and

- Creating and thinking critically- children have and develop their own ideas, make links between ideas, and develop strategies for doing things.

(DfE, 2012) 
The main objectives of the community therefore were to improve outcomes both for children and adults by:

- Increasing practitioners' understanding of and confidence in using the newly introduced Characteristics of effective learning.

- Enhancing early years practitioners' teaching skills particularly in promoting children's Creating and thinking critically (i.e. children's ability to 'have their own ideas', 'make links' and 'choose ways to do things'): this focus was informed by research evidence which indicates that this characteristic is linked to self-regulation, creativity and motivation (Whitebread et al., 2009).

- Developing a sustainable model of practitioner development and partnership that will support children's learning, particularly those in disadvantaged groups.

In order to realise these objectives the authors established a professional learning community comprising some 36 practitioners from 18 early years settings from within Camden who were keen to take advantage of the opportunity for developing the skills of their practitioners in this way. The aim of the learning community was to assist participating practitioners (two from each setting) in developing a wider repertoire of interactive strategies which better support children's creative and critical thinking. It was envisaged that such strategies would be formed from a combination of formal (academic) knowledge and praxis based best practice and subsequently throughout the year the enactment of these strategies would be observed, critiqued and improved upon via a process of facilitated lesson study. ${ }^{\text {iv }}$ The efficacy of these strategies in meeting their objectives (in terms of practitioner and children's outcomes) was then established via an evaluation process where baseline data was collected at the beginning of the project, intermediary data collected at monthly intervals and endline (outcome) data, collected at the project's 12-month conclusion. At the same time the authors also sought to use the evaluation process as a means of both testing: first, the learning community approach as a way of facilitating evidence-informed practice; and secondly (vitally), as a way of testing potential ways of measuring the success of our approach. In other words, to ascertain whether the knowledge creation approach had facilitated the development of expertise in terms of evidence use.

\section{Approach}

A knowledge creation workshop was held during the inaugural professional learning community meeting. Following Nonaka and Takeuchi (1995) and Stoll (2009) this involved 
researchers facilitating a discussion that firstly centred around current academic knowledge (both theoretical and empirical) in relation to effective early years practice (in itself this had been constructed via a literature review, specifically undertaken for the project: see Rogers and Brown, forthcoming). Practitioners were then invited to share their own practical knowledge, for example, data and insight about their settings and current practices, via exercises designed to surface this knowledge (see Rogers and Brown, forthcoming). They were subsequently invited to establish what they wanted to achieve by the end of the project and how they might do so: specifically, following an approach set out by Earley and Porritt (2013) and 'starting with the end in mind' (the goal they wished to achieve), practitioners were asked how they might use academic knowledge presented to them, their own practical knowledge, and knowledge provided by others in their study group, to produce strategies to reach this end-point.

Following this initial workshop, practitioners from the 18 partner settings were paired into six lots of three and during each term each setting hosted one visit for their study group. During each visit, each of these study groups (along with a facilitator) spent the morning of their session in the setting observing a specific lesson undertaken by the host practitioner. Before the lesson, the host practitioner briefed the observing practitioners in terms of what they wanted to achieve and what they wanted the outcomes to be. In the afternoon the group then reflected on the 'success' of the lesson and offered suggestions for how it might be improved as well as planning the next lesson study. In order to ensure research evidence remained top of mind, the facilitators were asked specifically to ensure that, as well as improvements grounded in practitioner knowledge, that they prompted for potential improvements suggested by the research. They did this through the use of non-specific questions, for example by asking things such as: 'and how might we incorporate what we know from the research here?' At the end of each lesson study day, all 36 participating practitioners came together for an end of the end of day seminar hosted by a research 'expert' (the second author) to ensure that learning was shared and reflected upon across the group. Where pertinent, the research expert would relate practitioner experiences shared during the feedback back session, to the research presented (i.e. to specific theories, approaches and authors).

\section{Methods}

The overall purpose of our methodological approach described in this paper (as distinct from those approaches employed as part of the overall evaluation) was to ascertain how effective the knowledge creation process was in instilling an evidence-informed ethos within a specific group of practitioners. To do so required us to establish ways of measuring impact in ways that addressed earlier critiques of this approach (as noted above). Specifically, as well as 
Levin's points, we wished to measure the extent to which practitioners had become expert in using evidence. As can be seen from figure 1, however (later below) the descriptors of each of Flyvbjerg's levels of expertise seemed tricky to operationalise. In other words to turn into scales that would be meaningful to respondents and that tackled the specific situation (i.e. that we were asking them to consider and then employ evidence as part of developing strategies to improve their practice). Ultimately, therefore, this quest led us to approaching the issue of measurement in two distinctive ways, with a subsequent phase of in-depth semi structured interviews and observation work, to provide additional insight and also data regarding the validity and reliability of our favoured approach.

Our first approach saw us draw upon a study successfully undertaken by Landry et al, (2003), who surveyed government officials from Canadian and provincial public administrations in order to examine the extent to which they employed academic research as part of the policy process. Landry et al. 's study based their measurement of research use on an adapted version the Knott and Wildavsky (1980) 'ladder of research' use (see 2003: 194); one recognised for its reliability (e.g. see Cherney et al., 2013). Correspondingly Landry et al. 's study is one grounded in the assumption that evidence use must be examined in terms of cumulative levels or stages of both cognitive process and action. In other words that evidence use doesn't just happen but occurs as process comprising many stages via a movement from its 'reception' ("I received the university research pertinent to my work") to 'Influence' ("university research results influenced [my] decisions”) via the stages of 'cognition', 'discussion', 'reference', and 'effort' ("I made efforts to favour the use of university research results"). This notion that use occurs gradually over time and is dependent on it being meaningfully 'received' or engaged with meant that we felt that the scale would provide a good basis to ascertain: i) how well research was initially communicated in the knowledge creation workshop; and) ii) on the back of this, the extent to which users were inclined to employ the research findings.

Our scale was amended, however to reflect the situation in which it was to be applied, in other words: i) that we were studying practitioners not policy makers; and ii) that we were asking practitioners to consider the research just presented and which they had been asked to employ in the development of their strategies in their study groups. This led us to employing the following descriptor terms:

1. Reception: the research was well communicated

2. Cognition: I understood the findings of the research

3. Discussion: I discussed with others within my study group how the research might be used 
4. Reference: I could relate the research findings to my setting

5. Effort: I used the research in subsequent exercises (when thinking about the approaches I might use in my setting)

6. Influence: I intend to apply/have applied the research as part of my approach

In order to collect data against our scale, a self-completion survey was employed at the end of the knowledge creation workshop (with the researchers in situ whilst the survey was being completed in order that we might address any questions or queries regarding interpretation). Specifically respondents were asked to consider all six elements and indicate the extent to which they agreed using five point Likert items, which ranged from 'strongly agree' to 'strongly disagree': the five point scale providing subtlety of understanding since it is grounded in the notion of knowledge use being a process containing multiple stages, rather than an event that can be measured in a yes/no binary way.

Respondents were also asked to respond to additional open response questions to enable us to ascertain what other factors had influenced their choice of strategies:

- Why respondents wanted to use the research findings discussed ('Why do you want to use the research?').

- 'What else was being discussed by the study group?'

- Whether these additional discussions were also drawn ('Did you also incorporate this into your strategies? How?' with respondents asked to reply 'Yes or No' and 'Please state how').

- Whether there was anything else that influenced their choice of strategies? ('Was there anything else that influenced your choice of strategies?' with respondents asked to reply 'Yes or No' and 'Please state what').

Our initial survey thus enabled us to establish initial thoughts regarding the strategies that practitioners hoped to create and the chance to ascertain the extent to which these had been influenced by the research that had been shared and engaged with, along with other potential influences and the relative strength of such influences. In total 33 of 36 participants completed the survey.

\section{Levels of Use}

Whilst our scale appeared to be a useful way of assessing the effectiveness of the knowledge creation activity as a means of communicating research and as a process of stimulating 
interest and a desire to use evidence, it failed, however, in terms of providing an ongoing measure. In particular, what it didn't do was enable us to determine whether, over time, the level of expertise of practitioners' use of evidence increased. In other words, it did not allow us to understand the effectiveness of the evidence combination we had produced. For example, to ascertain whether practitioners were being guided slavishly by the evidence or if they had combined it in a more intuitive, holistic way with their practical experience; meaning that their overall ability to understand or tackle particular situations had been enhanced. It also didn't provide a way of assessing changes in expertise over time: i.e. did practitioners begin as novices and gradually improve their expertise?

As a result, our second approach to measuring evidence use involved attempts to find (and if required amend) a scale that could be more closely related to Flyvbjerg's levels of expertise. Following Cherney et al., (2013) we sought out scales whose value lay in their ability to identify how utilisation is related to various on-going and complex (and indeed socially situated) decision-making processes, Our attempts culminated with a decision to use the Levels of Use scale developed by Hall and Hord (2001) as part of their wider work in developing the Concerns-Based Adoption Model (CBAM). ${ }^{\vee}$ The Levels of Use scale represents eight classifications relating to how people act or behave in response to a newly introduced change or innovation. Specifically, it reflects the observation that, just because it has been suggested or mandated that an innovation should be used, it doesn't mean that this will necessarily be the case, or that all individuals will be employing the innovation in the same way (with some users 'stumbling along' and others now using the innovation to achieve ground-breaking ends: Loucks et al., 1975). ${ }^{\text {vi }}$ This idea, that there are different typologies of use which occur as a function of users' ability to incorporate a new innovation into their practice, led us to believe that the Levels of Use scale might provide a way of understanding how notions of expertise might be expressed. In addition, however, it enabled us to develop a scale based on Hall and Hord's existing and extensive learning: for example, their insight that an eight point scale is more likely to capture subtlety in terms of the different ways in which innovations are used (Loucks et al., 1975).

As a result, Hall and Hord's approach and scale had an impact on our understanding as to expertise might be measured. For example, as Figure 1 indicates, while there does seem to be a level of congruence between Flyvbjerg and Hall and Hord, the expertise scale as it currently stands has to be 'stretched out' since certain stages of expertise appear to apply to a number of Hall and Hord's categories. Conversely, the language used in the Hall and Hord scale required modification so that it effectively captured the expertise that was being displayed by given types of use. For example, that a user was able to modify and augment an innovation in 
order to obtain greater impact implies a high level of connection between formal knowledge (the intervention) and the tacit (the practical understanding of the situation in hand): i.e. a high level of expertise. Of similar interest was whether modifications were undertaken consciously or unconsciously, with the latter suggesting even greater levels of expertise. At the same time, this modification meant that were able to tackle some of the critiques made of this scale: for example, Landry et al. 's (2003) suggestion that the Levels of Use scale focuses on specific uses of research. In other words we were able to ensure our revised scale examined changes in behavior that occur as a result of practitioners engaging with research as opposed to actual instances of research use.

\section{Figure 1: Congruence between Flyvbjerg and Hall and Hord}

Hord and Hall: levels of use concerning a new innovation

\begin{tabular}{|c|c|}
\hline Flyvbjerg: expertise that accrues through learning & $\begin{array}{l}\text { Non-use } \\
\text { The user has little or no knowledge of the innovation, no } \\
\text { involvement with the innovation, and is doing nothing towards } \\
\text { becoming involved }\end{array}$ \\
\hline Non-use & \\
\hline $\begin{array}{l}\text { Novice } \\
\text { i."rigid adherence to taught rules or plans" } \\
\text { ii.no exercise of "discretionary judgment" }\end{array}$ & $\begin{array}{l}\text { Orientation } \\
\text { The user has recently acquired or is acquiring information about the } \\
\text { innovation and/or has recently explored or is exploring its value } \\
\text { orientation and its demands upon user and user system. }\end{array}$ \\
\hline $\begin{array}{l}\text { Advanced beginner } \\
\text { i.limited "situational perception" } \\
\text { ii.all aspects of work treated separately with equal } \\
\text { importance }\end{array}$ & Preparation: The user is preparing for first use of the innovation \\
\hline $\begin{array}{l}\text { Competent } \\
\text { i."coping with crowdedness" (multiple activities, } \\
\text { accumulation of information) } \\
\text { ii.some perception of actions in relation to goals }\end{array}$ & $\begin{array}{l}\text { Changes in use are made more to meet user needs than client needs. } \\
\text { The user is primarily engaged in a stepwise attempt to master the } \\
\text { tasks required to use the innovation often resulting in disjointed or } \\
\text { superficial use. }\end{array}$ \\
\hline $\begin{array}{l}\text { Proficient } \\
\text { i.holistic vicw of situation }\end{array}$ & $\begin{array}{l}\text { Routine: Use of the innovation is stabilised. Few if any changes are } \\
\text { being made in ongoing use. Little preparation or thought is being } \\
\text { given to improving innovation use or its consequences. }\end{array}$ \\
\hline $\begin{array}{l}\text { ii.prioritizes importance of aspects } \\
\text { iii."perceives deviations from the normal pattern" } \\
\text { ivemploys maxims for guidance, with meanings that adapt } \\
\text { to the situation at hand }\end{array}$ & $\begin{array}{l}\text { Refinement: The user varies the use of the innowation to increase } \\
\text { the impact on clients [pupils/students] within immediate sphere of } \\
\text { influence. Variations are based on knowledge of both short- and } \\
\text { long-term consequences for clients [pupils/students]. }\end{array}$ \\
\hline $\begin{array}{l}\text { Expert } \\
\text { i.transcends reliance on rules, guidelines, and maxims } \\
\text { ii."intuitive grap of situations based on deep, tacit } \\
\text { understanding" } \\
\text { iii.has "vision of what is possible" } \\
\text { ivuses "analytical approaches" in new situations or in case of } \\
\text { problems }\end{array}$ & $\begin{array}{l}\text { Renewal: The user re-evaluates the quality of use of the } \\
\text { innovation, seeks major modifications of or alternatives to present } \\
\text { innovation to achieve increased impact on clients [pupils/students], } \\
\text { examines new development in the field, and explores new goals for } \\
\text { her/himself and the system. }\end{array}$ \\
\hline
\end{tabular}

of Use scale that sought elicit notions of expertise in relation to evidence-use: 
Figure 2: Typologies and descriptors of expertise: the 'expertise in evidence use' scale

\begin{tabular}{|c|c|c|}
\hline Hall and Hord & Flyvbjerg expertise & $\begin{array}{l}\text { New typology and descriptors } \\
\text { based on Hall and Hord and seeking to elicit expertise }\end{array}$ \\
\hline Non-use & Non-use & $\begin{array}{l}\text { NON-USE: I haven't attempted to use any of the findings from the } \\
\text { research within my day to day practice }\end{array}$ \\
\hline Orientation & Non-use & $\begin{array}{l}\text { ORIENTATION; I have begun to consider how to use some of the } \\
\text { findings of the research as part of my day to day practice. For example in } \\
\text { terms of specific strategies suggested by the research }\end{array}$ \\
\hline Preparation & Non-use to Novice & $\begin{array}{l}\text { PREPARATION: I have made concrete plans to use some of the } \\
\text { research findings as part of my day to day practice and am waiting for } \\
\text { the opportunity to do so. }\end{array}$ \\
\hline Mechanical use & $\begin{array}{l}\text { Novice to Advanced } \\
\text { beginner }\end{array}$ & $\begin{array}{l}\text { NOVICE: I have now begun to implement specific strategies suggested } \\
\text { by the research within my day to day practice. }\end{array}$ \\
\hline Routine & Competent & $\begin{array}{l}\text { COMPETENT: I now regularly use some of the research findings within } \\
\text { my day to day practice. For example I frequently use specific strategies } \\
\text { suggested by the research. }\end{array}$ \\
\hline Refinement & Proficient & $\begin{array}{l}\text { PROFICIENT: I have begun to tailor my use of the research findings so } \\
\text { that I can incorporate other aspects of effective practice that I know } \\
\text { about. }\end{array}$ \\
\hline $\begin{array}{l}\text { Integration to } \\
\text { Renewal }\end{array}$ & Proficient to Expert & $\begin{array}{l}\text { PROFICIENT +: I regularly adapt the strategies suggested by the } \\
\text { research in order to make them even more effective or so that they can } \\
\text { apply to a number of situations within my setting. }\end{array}$ \\
\hline - & Expert & $\begin{array}{l}\text { EXPERT: I frequently use the research strategies we learnt about but I } \\
\text { now incorporate them into my day to day practice in an automatic rather } \\
\text { than conscious way, as I tackle specific situations and issues. }\end{array}$ \\
\hline
\end{tabular}

Again, respondents were asked to consider all eight elements and indicate the extent to which they agreed with them using a scale that ranged from 'strongly agree' to 'strongly disagree'. This enabled us to establish a more nuanced understanding as to whether a level of expertise had been reached and, as a result, an understanding of 'typologies' of evidence use being displayed by respondents. The survey was administered in December 2013, some four months after the beginning of the project. In total 34 of 36 participants completed the survey.

\section{In-depth semi-structured interviews and the analysis of facilitator observations}

To explore the evidence use typologies emerging from the survey in more detail, we engaged in two activities. The first was semi-structured in-depth interviewing. The purpose of the interviews, was two-fold: 1) to explore the actions and behaviours of individuals at different levels of expertise (as indicated via their survey responses); 2), to explore the 'trustworthiness' of the 'expertise in evidence use' scale by asking questions to assess comprehension of the questions and whether the questions were measuring what they were designed to measure. In total, 10 interviews were undertaken. Second, we analyzed the meeting notes made by the project's facilitators (other than the paper's authors). These notes detail facilitators' observations on both participants' practice and thoughts during the lesson 
study days. Correspondingly, they provide an independent indication of how participants' practice changed during the project.

\section{Findings}

Beginning with results from our amended 'ladder of use' scale, it can be seen in table 1, below, that all respondents agreed or strongly agreed that the research was well communicated; comprehension too was high with $94 \%$ agreeing or strongly agreeing that they understood what had been communicated (no respondents disagreeing or strongly disagreeing with this statement). This pattern continues until stage 4 of the ladder ('I can see how the research related to my setting') where three per cent disagree; correspondingly this same three percent disagreed that they felt that they had started to use the research in subsequent exercises (stage 5) or had any intention of using the research moving forward (stage 6). Conversely $97 \%$ suggested that had actively discussed the research presented (stage 3); $94 \%$ could see its relevance and had discussed the research in the exercises throughout the day (stages 4 and 5); and 97\% expressed the intention to use findings as they developed approaches and strategies for their setting (stage 6).

Table 1: Findings from the amended 'ladder of use' scale $(n=33)$

\begin{tabular}{|l|r|r|r|r|r|r|}
\hline Stage & $\begin{array}{r}\text { Strongly } \\
\text { disagree }\end{array}$ & \multicolumn{1}{c|}{ Disagree } & Neither & Agree & $\begin{array}{c}\text { Strongly } \\
\text { agree }\end{array}$ & \multicolumn{1}{c|}{ Total } \\
\hline Reception & $-\%$ & $-\%$ & $-\%$ & $58 \%$ & $42 \%$ & $100 \%$ \\
\hline Cognition & $-\%$ & $-\%$ & $6 \%$ & $61 \%$ & $33 \%$ & $100 \%$ \\
\hline Discussion & $-\%$ & $-\%$ & $3 \%$ & $70 \%$ & $27 \%$ & $100 \%$ \\
\hline Reference & $-\%$ & $3 \%$ & $3 \%$ & $48 \%$ & $45 \%$ & $100 \%$ \\
\hline Effort & $-\%$ & $3 \%$ & $3 \%$ & $63 \%$ & $31 \%$ & $100 \%$ \\
\hline Influence & $-\%$ & $3 \%$ & $-\%$ & $45 \%$ & $52 \%$ & $100 \%$ \\
\hline
\end{tabular}

To follow up on stage 6, we asked an open ended question: 'why do you want to use research' and inductively coded the responses. Here the majority suggested that use was related either to enhance the 'general' or generic quality of their practice (46\%). One fifth (20\%), meanwhile, wanted to use the findings to augment specific areas of their work that they felt needed improving (in addition, six percent wanted to use the research to help them improve the practice of others in their setting). Other responses included a desire to better understand a particular aspect of child development (six percent); to develop evidence informed practice (three percent); while one more cynical respondent suggested that the findings would be useful to back up changes that had already been made. 
Finally, we examined what else had been discussed within the group exercises: here responses mainly centred on 'general discussion on the EYFS' (32\%) with others low in their frequency of mention, but ranging in terms of topic from 'extending children's interests to 'notions of quality'. Importantly, however, just over a third of respondents (36\%) indicated that these discussions were pertinent and did influence how they developed ideas and strategies for their settings; the same number also suggesting that their strategies were also informed by their practitioner knowledge (i.e. knowledge of their children and setting).

\section{Levels of use}

Moving now to our combined expertise and levels of use scale, findings here are presented in table 2, below. In administering the survey it was explained to participants that each question built on from the next. Correspondingly we explained that, if participants felt that they had already reached a level that they should agree (or strongly agree) with the statement - with this process continuing until respondents felt that they hadn't engaged or behaved in this way. As can be seen and as you might expect after four months of activity, the majority (88\%) of respondents indicated that they had made attempts to use at least some of the research presented as part of their day to day practice. Following this, however (and again as you might expect, assuming that generally there will be fewer people at the highest levels of expertise) there is a steady decline in the percentage of respondents agreeing or strongly agreeing with the statements regarding positive research use. This decline finally culminates in only one third of participants scoring themselves as experts. In more detail then, it can be seen that as we progress through the questions $94 \%$ agree or strongly agree that their use was around 'orientation' - considering how research findings might be implemented. The level of agreement falls to $77 \%$ for 'preparation' - making plans to use findings. Two thirds (65\%) suggest they are 'proficient', i.e. beginning to tailor the research findings so that they are contextually appropriate. At the highest levels of expertise only $47 \%$ agreed (no-one strongly agreed) that they were regularly adapting the strategies suggested by the research in order to make them even more effective ('proficient +'). Finally, as mentioned above, only 35\% agreed (no-one strongly agreed) with the statement relating to full expertise: 'I have used the research strategies we learnt about so often now that I barely need to even think about them, they've just become part of my day to day practice.'

Table 2: Findings by typology, derived from the combined expertise and levels of use scale $(\mathbf{n}=34)$

\begin{tabular}{|l|r|r|r|r|r|r|}
\hline Descriptor & $\begin{array}{c}\text { Strongly } \\
\text { disagree }\end{array}$ & Disagree & Neither & Agree & $\begin{array}{c}\text { Strongly } \\
\text { agree }\end{array}$ & Total \\
\hline Non-use & $35 \%$ & $53 \%$ & $6 \%$ & $-\%$ & $6 \%$ & $100 \%$ \\
\hline
\end{tabular}




\begin{tabular}{|l|r|r|r|r|r|r|}
\hline Orientation & $6 \%$ & $-\%$ & $-\%$ & $88 \%$ & $6 \%$ & $100 \%$ \\
\hline Preparation & $-\%$ & $12 \%$ & $12 \%$ & $65 \%$ & $12 \%$ & $100 \%$ \\
\hline Novice & $-\%$ & $-\%$ & $29 \%$ & $59 \%$ & $12 \%$ & $100 \%$ \\
\hline Competent & $-\%$ & $6 \%$ & $19 \%$ & $63 \%$ & $13 \%$ & $100 \%$ \\
\hline Proficient & $-\%$ & $-\%$ & $35 \%$ & $53 \%$ & $12 \%$ & $100 \%$ \\
\hline Proficient + & $-\%$ & $12 \%$ & $41 \%$ & $47 \%$ & $-\%$ & $100 \%$ \\
\hline Expert & $6 \%$ & $12 \%$ & $47 \%$ & $35 \%$ & $-\%$ & $100 \%$ \\
\hline
\end{tabular}

\section{Interview data}

Due to the Christmas break the interviews were held almost two months after the survey was administered and were focused on our combined scale. Participants were re-issued with the survey to remind them as to its contents and were also reminded of their responses. All agreed that our combined scale 'made sense' to them; the only issue raised being the 'flow' of the first two questions. Specifically the change in the emphasis from the first question - this related to 'non use' and asked respondents to agree or disagree with an statement suggesting they hadn't acted ('I haven't attempted...') to the second question on 'orientation' which instead related to positive action ('I have attempted...'). Interestingly, whilst agreeing that, theoretically at least, expertise in evidence use might build over time, the length of gap between completion and interview also meant that some respondents were able to identify changes in their behavior: "just looking through the questions again, I can see plenty now that I wouldn't have been able to [tick 'agree' on] before" (interviewee \#6). For example, those at the lower end of the scale were now revisiting in detail the research that was introduced at the beginning of the project, often this was part of an overall process of sharing new pedagogic approaches with colleagues: "we've run a whole INSET day to show staff what've found... and demonstrate some of the new approaches that have emerged" (interviewee \#2).

Others, when asked if they felt they might reach the level of expertise implied by the top end of the scale suggested that they believed they were now "getting there" (interviewee \#4). For example, one noted: "when we are engaged in the activities, I now think to myself 'don't rush' and that, thinking about it, was something that came as a result of listening to the research and in discussing how to do this with the study group... it [the research] just comes to me straight away now" (interviewee \#5). Others discussed the strategies developed within the study group as becoming "second nature" (interviewee \#1). As a result because they could now relate this type of change to their actual behavior, respondents felt strongly that the scale reflected how expertise in using evidence as part of practice develops over time. 


\section{Analysis of meeting notes}

We are able to augment the findings presented above through an analysis of the meeting notes made by the project's facilitators, which detail their observations both on participants' practice and thoughts during the lesson study days. Whilst the meeting notes do not provide instances of changes in practice that correspond directly against the 'expertise in evidence use' scale (as this was not something we had asked them to do), they do provide some concrete examples of how early years practitioners were, by the end of the project, beginning to engage with early years research and evidence in deep and complex ways (especially in comparison to when the project commenced). For example, at the beginning of the project (during the September knowledge creation workshop), one facilitator noted "for some participants there was a lot of unfamiliar terminology and research [that was] referred to..." They also noted their concern regarding practitioners' confidence to engage with this research. By November however, notes from the same facilitator indicate that "now on Fridays [one early years setting] is using a Reggio Emilio approach ${ }^{\text {vii }}$ and taking out all the furniture [sic] so that they can explore paint on the floor". In other words, that the practitioners they had been observing were engaging with key aspects of a well researched educational approach that had been explored as part of the initial knowledge creation activity. Another facilitator recorded in their November notes, one participant explaining that: "you plan from [the children's] interests but what will they learn from bathing a baby... [instead I have now started looking at] Vygotsky, schemas and other research. So we've set up a language corner. There's a nursery rhyme of every nationality of the children in the room. We have French and Spanish on Fridays".

In December observations from facilitators included the discussion by one participant that they were now, when planning for activities: "thinking more deeply about why [they were] doing the activities for the children, what [they wanted] the children to learn, how [they were] supposed to talk to the children (open ended questions)...[and] what they were supposed to be expecting to happen". Another participant suggested that: "I've learnt in-depth more about how children learn, really been interested in zone play development [sic]"; and that that they had gained a great from engaging with "pedagogies of learning such as scaffolding and coconstruction". Finally one of the few participants in the project with a graduate level qualification was noted as saying that she had been inspired to "research some theories that I learned some time ago and review them... and to use [them] more for my daily practice. I am more aware of my attitude towards the children, giving more space and freedom on their choices... and not asking too many questions before letting children have the opportunity to think for themselves". Again these points nicely illustrating that participants were not only engaging with research and related theories of learning, such as those based on Vygotsky, but 
that this engagement was being undertaken at more than just a surface level or in a slavish 'what works' type way. In other words, that as a result of participants engaging in knowledge creation activity, that this approach to engaging with evidence was affecting their practice in intuitive and deep ways.

\section{Discussion}

What we have presented represents simply an initial attempt to establish ways of measuring: i) meaningful evidence-use - defined as the result of combining formal and practitioner knowledge such that this leads to expertise; ii) the effectiveness of knowledge creation activity as a means of establishing meaningful evidence-use. Nonetheless, based on the results of the two surveys outlined above, our findings would appear to be encouraging: not only does knowledge creation activity seem to provide an effective way of communicating research and keeping it top of mind; but because it helps practitioners combine (in practical ways) formal knowledge with practice-based or tacit knowledge, it would seem to enable them to develop expertise in using evidence. Simultaneously our interview and observation data would appear to triangulate and verify the trustworthiness of measures used in the surveys as a way of measuring levels of expertise in evidence use (Lincoln and Guba, 1985). In other words provides us with confidence that not only is our approach to measurement 'valid' but as a result that it meaningfully represents the level of expertise captured: i.e. we are confident in our claim that knowledge creation works to establish expertise in evidence use. In addition, by using both the ladder of use scale and an amended 'levels of use' scale we believe we have tackled the issues regarding 'self report' raised by Levin above. Namely, rather than examine participants' perceptions of instrumental research use (what people believe they did) we ask participants to make statements in relation to their present behavior: how they are currently responding in relation to an ongoing activity. This ensures we are looking at research use as process rather than event (Landry et al., 2003)

At the same time the approach we have developed to assess expertise in evidence use does have its limitations: namely, that it is only really applicable to situations where researchers are working regularly with practitioners on areas of practice development, where the general desire is that these areas should become evidence-informed. In other words it measures the effectiveness of activity to engage practitioners with evidence rather than more generally whether practitioners are expert evidence users. At the same time, however, this does not mean that our approach has relevance only to relatively few instances of initiatives or activity. On the contrary in school systems such as England's, where the expectation is that schools or alliances of schools should lead their professional development activity, often in partnership with (or drawing on the help of) universities, it is likely that these instances will soon be 
increasing in number (Greany, 2014); similarly the scale could be equally meaningful as a way to measure the extent to which practitioners have engaged with the findings of practitioner enquiry or action research. As such, we suggest that the scale we have set above will soon play a vital part in helping establish whether 'self-improving' school systems (Hargreaves, 2010) are also those that are meaningfully evidence informed.

\section{References}

Biesta, G. (2007) Why 'What Works' Won't Work: Evidence-based Practice and the Democratic Deficit in Educational Research, Educational Theory, 57, 1, pp. 1-22.

Brown, C. (2013) Making Evidence Matter: A New Perspective on Evidence-Informed Policy Making in Education, (London, IOE Press).

Brown, C. (2014) Evidence Informed Policy and Practice in Education. A Sociological Grounding, (London, Bloomsbury).

Cartwright, N. (2013) Knowing what we are talking about: why evidence doesn't always travel, Evidence \& Policy, 9, 1, pp. 97-112.

Cherney, A., Povery, J., Head, B., Boreham, P. and Ferguson, M. (2012) What influences the utilisation of educational research by policy-makers and practitioners?: The perspectives of academic educational researchers, International Journal of Educational Research, 53, pp. 2334.

Cooper, A., Levin, B. and Campbell, C. (2009) The growing (but still limited) importance of evidence in education policy and practice, Journal of Educational Change, 10, 2-3, pp. 159171.

Department for Education (2012) Early Years Foundation Stage Framework 2012, available via http://www.foundationyears.org.uk/early-years-foundation-stage-2012/, accessed on 8 July 2012.

Earl, L. and Timperley, H (2008) Understanding how evidence and learning conversations work, in: Earl, L. and Timperley, H (Eds) Professional Learning Conversations: Challenges in Using Evidence for Improvement, (Springer).

Earley, P. and Porritt, V. (2013) Evaluating the impact of professional development: the need for a student-focused approach, Professional Development in Education, DOI: $10.1080 / 19415257.2013 .798741$

Flyvbjerg, B. (2001) Making Social Science Matter (Cambridge, Cambridge University Press).

Goldacre, B. (2013) Building evidence into education, available at: https://www.gov.uk/government/news/building-evidence-into-education, accessed on 27 January 2014.

Greany, T. (2014) Are we nearly there yet? Progress, issues and next steps for a selfimproving system, inaugural professorial lecture to the Institute of Education, 18 March 2014. 
Hall, G. E. and Hord, S.M. (2001) Implementing Change: Patterns, Principles and Potholes. Boston: Allyn and Bacon.

Hargreaves, D. (1996) The Teaching Training Agency Annual Lecture 1996: Teaching as a research based profession: possibilities and prospects, available at:

http://eppi.ioe.ac.uk/cms/Portals/0/PDF\%20reviews\%20and\%20summaries/TTA\%20Hargrea ves\%20lecture.pdf, accessed on 14 January 2013.

-- (2010) Creating a self-improving school system, (Nottingham, National College for School Leadership).

Hillage, L., Pearson, R., Anderson, A. and Tamkin, P. (1998) Excellence in Research on Schools, (London: DfEE).

Knott, J. and Wildavsky, A. (1980) If dissemination is the solution, what is the problem?, Knowledge: Creation, Diffusion, Utilization, 1, 4, pp. 537-78.

Landry, R., Amara, N., and Lamari, M. (2003) The Extent and Determinants of Utilization of University Research in Government Agencies, Public Administration Review, 63, 2, pp. $192-$ 205.

Levin (2013) To know is not enough: research knowledge and its use, Review of education, 1 , 1, pp. 2-31.

Lincoln, Y., and Guba, E. (1985) Naturalistic Inquiry, (Newbury Park, CA, Sage Publications).

Loucks, S. F., Newlove, B. W. and G. E. Hall (1975) Measuring levels of use of the innovation: a manual for trainers, interviewers and raters. Austin: The University of Texas. Research and Development Center for Teacher Education.

MacLure, M (2005). 'Clarity bordering on stupidity': where's the quality in systematic review?, Journal of Educational Policy, 20, 4, pp. 393-416.

März, V. and Kelchtermans, G. (2013) Sense-making and structure in teachers' reception of educational reform. A case study on statistics in the mathematics curriculum, Teaching and Teacher Education, 29, pp. 13-24.

Nonaka, I. and Takeuchi, H. (1995) The knowledge creating company: how Japanese companies create the dynamics of innovation, (New York, Oxford University Press).

Nutley, S.M., Walter, I. and Davies, H.T.O. (2007) Using evidence: How research can inform public services, (Bristol, The Policy Press).

Rexvid, D., Blom, B., Evertsson, L. and Forssen, A. (2012) Risk Reduction Technologies in General Practice and Social Work, Professions and Professionalism, 2, 2, pp. 1-18.

Rogers, S. (2014) An enabling pedagogy: meanings and practices, in Moyles, J., Payler, J. and Georgeson, J. (Eds) Early Years Foundations: Critical Issues, (Maidenhead, Open University Press).

Rogers, S. and Brown, C. (forthcoming) Developing Early Years Learning and Pedagogy: an evaluation report, unpublished report for Camden Partnership for Excellence in Education.

Stoll, L. (2008) Leadership and policy learning communities: promoting knowledge 
animation, in: Chakroun, B. and Sahlberg, P. (eds) Policy learning in action: European Training Foundation Yearbook 2008, (Torino, Italy, European Training Foundation).

-- (2009) Knowledge Animation in Policy and Practice: Making Connections, Paper presented at the Annual Meeting of the American Educational Research Association as part of the symposium Using Knowledge to Change Policy and Practice, available at:

www.oise.utoronto.ca/rspe/UserFiles/File/Publications\%20Presentations/AERA\%2009\%20kn owledge\%20animation\%20paper\%20Stoll.pdf, accessed on 23 January, 2014.

-- (2012) Stimulating Learning Conversations, Professional Development Today, 14, 4, pp. 612.

Stoll, L., Bolam, R., McMahon, A., Wallace, M. and Thomas, S. (2006) professional learning communities: a review of the literature, Journal of Educational Change, 7, pp. 221-258.

Tooley, J. and Darby, D. (1998) Educational Research: a Critique, (London, Ofsted).

Virtanen, A. and Tynjälä, P. (2008) Students' experiences of workplace learning in Finnish VET. European Journal of Vocational Training, 44, pp. 199-213.

Whitebread, D., Coltman, P., Pino Pasternak, D., Sangster, C., Grau, V., Bingham, S., Almeqdad, Q. and Demetriou, D. (2009) The development of two observational tools for assessing metacognition and self-regulated learning in young children, Metacognition and Learning, 4, 1, pp 63-85

\footnotetext{
${ }^{i}$ See: http://www.education.gov.uk/childrenandyoungpeople/families/b00203759/evidencebased-practice, accessed on 10 January 2014.

ii These levels are i) novice; ii) advanced beginner; iii) competent performer; iv) proficient performer and v) expert.
}

iii See: https://www.gov.uk/government/policies/improving-the-quality-and-range-ofeducation-and-childcare-from-birth-to-5-years/supporting-pages/early-years-foundation-stage, accessed on 17 February, 2014.

${ }^{\text {iv }}$ Lesson study has been described as a process involving groups of practitioners collaboratively planning, teaching, observing and analyzing learning and teaching in research lessons. See: http://lessonstudy.co.uk/ for further detail.

${ }^{\mathrm{v}}$ That this scale might help the lead author operationalise measures of expertise was highlighted by Professor Louise Stoll who was aware of the lead author's interest in this area. Similarly, Landry et al., (2003) have also pointed to the Hall and Hord levels of use scale as an acknowledged approach used to examine knowledge 'utilisation'

${ }^{\text {vi }}$ Further detail on how the scales were developed and tested can be found in Loucks et al., (1975).

vii The Reggio Emilia Approach is an educational philosophy focused on preschool education in one small region of Northern Italy. Its principles are documented in Edwards, C., Gandini, L. and Forman, G. (Eds) (2012) The Hundred Languages of Children: Reggio Emilia in Transformation, $3^{\text {rd }}$ edition (California: ABC-CLIO). 